\title{
Co-optimized trading of hybrid wind power plant with retired EV batteries in energy and reserve markets under uncertainties
}

Zhan, Sen; Hou, Peng; Enevoldsen, Peter; Yang, Guangya; Zhu, Jiangsheng; Eichman, Joshua; Jacobson, Mark Z.

Published in:

International Journal of Electrical Power and Energy Systems

Link to article, DOI:

10.1016/j.ijepes.2019.105631

Publication date:

2020

Document Version

Peer reviewed version

Link back to DTU Orbit

Citation (APA):

Zhan, S., Hou, P., Enevoldsen, P., Yang, G., Zhu, J., Eichman, J., \& Jacobson, M. Z. (2020). Co-optimized trading of hybrid wind power plant with retired EV batteries in energy and reserve markets under uncertainties. International Journal of Electrical Power and Energy Systems, 117, [105631].

https://doi.org/10.1016/j.ijepes.2019.105631

\section{General rights}

Copyright and moral rights for the publications made accessible in the public portal are retained by the authors and/or other copyright owners and it is a condition of accessing publications that users recognise and abide by the legal requirements associated with these rights.

- Users may download and print one copy of any publication from the public portal for the purpose of private study or research.

- You may not further distribute the material or use it for any profit-making activity or commercial gain

- You may freely distribute the URL identifying the publication in the public portal 


\title{
Co-optimized Trading of Hybrid Wind Power Plant with Retired EV Batteries in Energy and Reserve Markets under Uncertainties
}

\author{
Sen Zhan ${ }^{\mathrm{a}}$, Peng Hou ${ }^{\mathrm{b}, *}$, Peter Enevoldsen ${ }^{\mathrm{c}}$, Guangya Yang ${ }^{\mathrm{a}}$, Jiangsheng Zhu ${ }^{\mathrm{b}}$, Joshua Eichman ${ }^{\mathrm{d}}$, Mark Z. Jacobson ${ }^{\mathrm{e}}$ \\ ${ }^{a}$ Center of Electrical Engineering, Technical University of Denmark, Denmark \\ ${ }^{b}$ SEWPG European Innovation Center, Denmark \\ ${ }^{c}$ Centre for Energy Technologies, Aarhus University, Denmark \\ ${ }^{d}$ National Renewable Energy Laboratory, USA \\ ${ }^{e}$ Department of Civil and Environmental Engineering, Stanford University, USA
}

\begin{abstract}
To be competitive in the electricity markets, various technologies have been reported to increase profits of wind farm owners. Combining battery storage system, wind farms can be operated as conventional power plants which promotes the integration of wind power into the power grid. However, high expenses on batteries keep investors away. Retired EV batteries, fortunately, still have enough capacity to be reused and could be obtained at a low price. In this work, a two-stage optimization of a wind energy retired EV battery-storage system is proposed. The economic performance of the proposed system is examined concerning its participation in the frequency containment normal operation reserve (FCR-N) market and the spot market simultaneously. To account uncertainties in the wind farm output, various electricity market prices, and up/down regulation status, a scenario-based stochastic programming method is used. The sizing of the equipment is optimized on top of daily operations of the hybrid system which formulates a mixed-integer linear programming (MILP) problem. Scenarios are generated with the Monte Carlo simulation (MCS) and Roulette Wheel Mechanism (RWM), which are further reduced with the simultaneous backward method (SBM) to increase computational efficiency. A $21 \mathrm{MW}$ wind farm is selected as a case study. The optimization results show that by integrating with a retired EV battery-storage system (RESS) and a bi-directional inverter, the wind farm can increase its profits significantly when forwarding bids in both of the aforementioned electricity markets.
\end{abstract}

Keywords: retired EV battery-storage system (RESS), FCR-N market, spot market, MILP

\section{Nomenclature \\ Indices \\ $\omega \quad$ Scenario index \\ $d \quad$ Day index from $1-365$ in a year \\ $i \quad$ Uncertain parameter index \\ $j \quad$ Interval index \\ $t \quad$ Hour index from $1-24$ in a day}

\section{Parameters}

$\alpha$

The ratio between the retired EV battery price and the brand new battery price

$\delta^{3} \quad$ Binary numbers indicating if power generation is over 0.3 MW

$\delta^{4} \quad$ Binary numbers indicating if FCR-N market price is over $80 \%$ of spot market price

$\delta^{5} \quad$ Binary numbers indicating if spot market price is non-positive

${ }^{*}$ Corresponding author at: SEWPG European Innovation Center, 8000 Aaruhus, Denmark

Email addresses: s181239@student.dtu.dk (Sen Zhan), houpeng@shanghai-electric.com (Peng Hou),

peter. enevoldsen@envisionenergy.dk (Peter Enevoldsen),

gyy@elektro.dtu.dk (Guangya Yang), guaz@dtu.dk (Jiangsheng Zhu),

joshua.eichman@nrel.gov (Joshua Eichman), jacobson@stanford.edu

(Mark Z. Jacobson) $\delta^{u p}, \delta^{\text {down }}$ Binary numbers used to indicate upward/downward regulation

$\eta^{c h}, \eta^{\text {dis }} \quad$ RESS charge/discharge efficiency

$\eta^{i n v} \quad$ Inverter efficiency for both directions

$\eta^{u p}, \eta^{\text {down }} \quad$ Percentages of activated power to bidden capacity for upward/downward regulation

$\lambda^{E V B} \quad$ Brand new EV battery price

$\lambda^{i n v} \quad$ Inverter price

$E^{E V B} \quad$ Brand new battery capacity

EP Spot market price

FCRN The FCR-N market price

$M \quad$ Arbitrarily big number in big M method

$P^{w t} \quad$ Power generation

$R P P^{\text {down }} \quad$ Downward regulating power price

$R P P^{u p} \quad$ Upward regulating power price

$\mathrm{SoH} \quad$ The ratio between the usable capacity of degraded battery and the nominal capacity

$T \quad$ Scenario span, 24 hours

Variables

$\delta^{1}, \delta^{2} \quad$ Binary variables indicating if bid is made to FCR$\mathrm{N}$ market

$\delta^{c h}, \delta^{\text {dis }} \quad$ Binary variables indicating charging/discharging state of RESS

Random numbers generated in the simulation 


$\begin{array}{ll}\pi & \text { Scenario probability } \\ E^{\text {charge }} & \text { Absolute charge content of the RESS } \\ E^{\text {RES }} & \text { RESS capacity } \\ N & \text { Optimized battery number of RESS } \\ P^{\text {acti,up }} & \text { Potential electricity inflow into FCR-N market } \\ & \text { from upward regulation } \\ P^{\text {ch,down }} & \text { Potential electricity inflow into RESS from down- } \\ & \text { ward regulation } \\ P^{\text {ch,up }} & \text { Potential electricity inflow into RESS from upward } \\ & \text { regulation } \\ P^{\text {ch,wt }} & \text { The power that is used for charging RESS from } \\ & \text { wind farm } \\ P^{\text {ch }} & \text { The charging power for RESS } \\ P^{\text {dis }} & \text { The power discharged from RESS } \\ P^{\text {inv }} & \text { The bi-directional inverter power } \\ P^{\text {spot,wt }} & \text { The power traded in spot market generated from } \\ & \text { wind farm } \\ P^{\text {spot }} & \text { Bidden electricity in spot market } \\ R & \text { The bidden capacity for upward regulation } \\ S o C & \text { State of charge } \\ Z & \text { Binary variables indicating options being chosen }\end{array}$

\section{Introduction}

Electrical Vehicles (EVs) have been scoped as the transition transportation technology to replace internal combustion engine vehicles (ICEVs) [1,2], however, despite academic consensus, the deployment of EVs remains low with a representation of, less than $1 \%$ of the combined global vehicle fleet [3]. Multiple reasons for the slow transition have been examined ranging from battery performance [2], vehicle costs [4], range limitations [5], etc., and are frightening similar as determined a decade ago [6]. Simultaneously, advocates for EVs have been using the arguments of vehicle-to-grid (V2G), which enables strategic storing and exchange of electricity [4]. However, few, if any studies have adequately examined the potential usage of EVs and EV batteries after the expired lifetime in combination with multi-megawatt wind turbines. Instead recent studies have focused on the combination of PV and retired EV batteries, and found that a) residual capacities can be exploited [7], b) power management and selection strategies are required to optimize the value of the retired battery [8], and c) the environmental, social and economic profiles of EV batteries are improved due to a minimization of the recycling rate [9]. Assuming the same consequences for retired EV batteries, it would inevitably increase the value of lifetime EVs, and potentially add to the policy mechanisms, which especially seems to be lacking in Denmark [1]. As a matter of fact, only 8,746 EVs (plug-in hybrids and all-electric vehicles) were registered in Denmark by the end of 2017 [10], which is far less than the Scandinavian neighbours Norway $(209,122)$ [11] and Sweden $(50,304)$ [12]. This being despite the fact that Denmark has excellent wind resources [13], a high penetration of wind power in its electricity mix (44\% of the demand in 2017) [14], and several days with a surplus of electricity and thereby negative electricity prices [15].

Using batteries for electrical storage system (ESS) is not a novel thought, and especially lithium-ion battery was brought up in several studies as a prominent technology for load shifting and peak shaving demands [16-19], and highlighted for its capabilities of low standby losses and high energy efficiencies $(60-95 \%)$ [20]. Using batteries to increases the profitability of wind farms have also been proposed before [21], as several studies demonstrated methods for lucrative bidding strategies on the day-ahead markets when combining batteries and wind farms [22, 23]. Furthermore, applying batteries as the cornerstone technology in ESS was concluded to be the most profitable approach to provide primary frequency service in the Danish reserve electricity market almost a decade ago [24].

This study will investigate solutions to a) The fluctuations in Danish electricity prices due to the heavy reliance on wind power, and b) The investment opportunities of installing retired EV batteries in Danish operational offshore wind farms.

In order to examine such challenges, the hybrid wind farm - retired EV batteries system is expected to participate in both the day-ahead and the FCR-N market. As a comparison, another case in which the wind farm only participates in the spot market is also studied, both shown in Fig. 1. According to the rule of Danish transmission system operating, the balance responsible parties (BRPs, referring to the hybrid system in this study) merely need to provide a small amount of energy to mitigate the frequency deviation and get remunerated mainly by the bidden power capacity. Therefore, the electricity generated from the wind turbines can be sold at the spot market or caters for upward regulations of the FCR-N market, with part energy or the surplus going into the RESS or possibly both.

Since discharging the battery will incur high cost and reduce the battery lifetime and performance obviously, the RESS works as downward regulation medium and receives electricity from the FCR-N market when downward regulation is needed. The upward regulation in the FCR-N market can be handled by controlling the wind turbines in the de-rated mode and releasing those when needed.

The research materials and methods are based upon the examination of the potential profitability of integrating retired EV batteries in a Danish operational offshore wind farm. Furthermore, web searches have been conducted to inform about statistics of EVs and the market prices in Denmark. The following sections describes the methodology and materials applied for the core elements of this research.

\section{Problem Formulation}

In this work, a scenario-based stochastic programming method is employed to cope with the inherent uncertainties of the optimization problem, including the power generation, the spot market prices, the FCR-N market prices, the regulating market (upward and downward) prices and the FCR-N service activation states. The framework has been examined in [25, 26] and concluded to be an efficient and effective method to account uncertainties for scheduling problems. To convexify the problem, the big $\mathrm{M}$ method is adopted to linearize the bi-linear term. The scenario generation and reduction are specified at the beginning of this part while the mathematical model of the optimization problem is given in the end. 


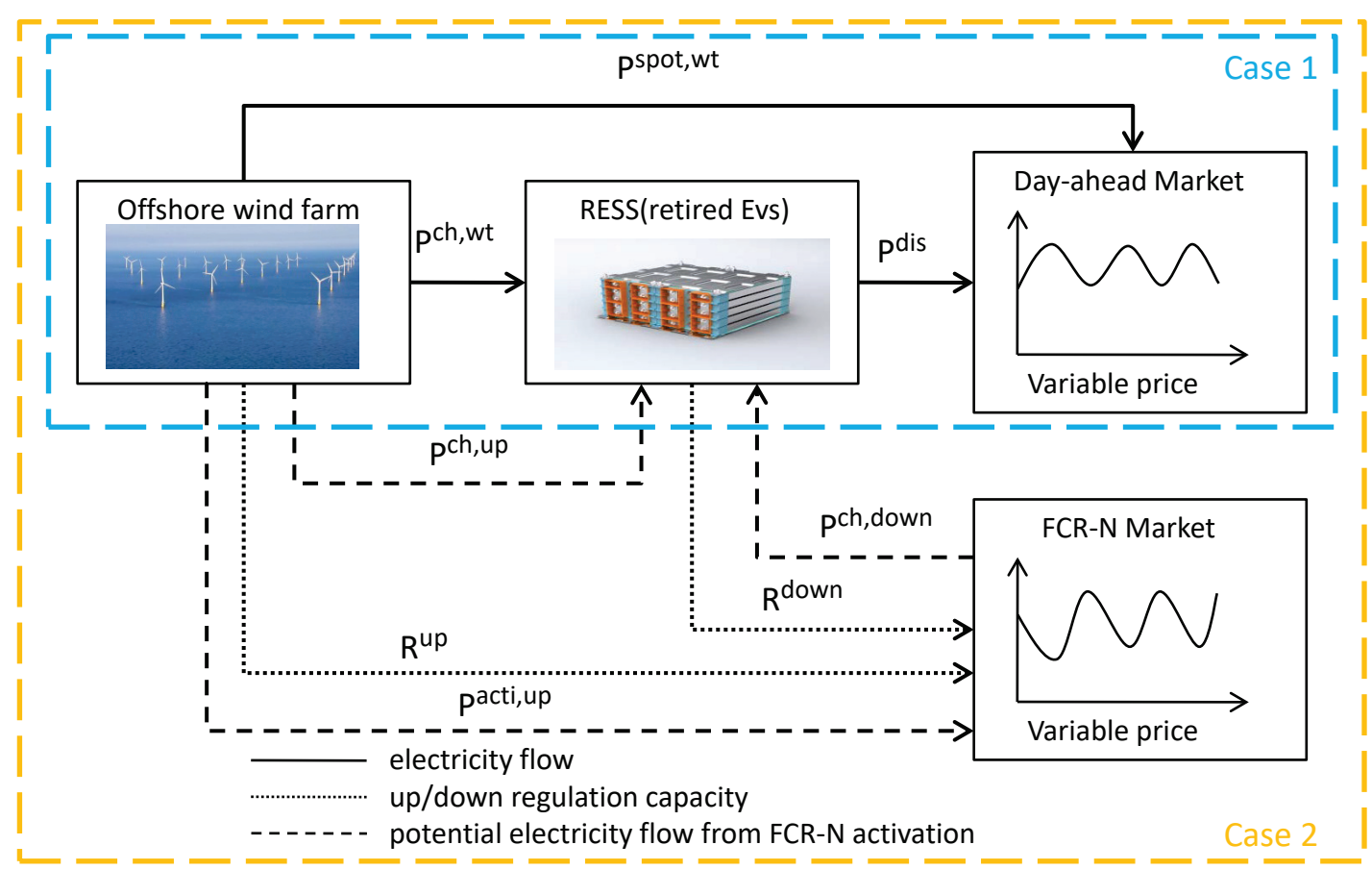

Figure 1: Hybrid wind farm-RESS system schematic layout

\subsection{Scenario generation}

The uncertain parameters listed in the previous paragraph are determined with generated scenarios by Monte Carlo Simulation (MCS) and Roulette Wheel Mechanism (RWM). Although other methods such as rejection method [27] and alias method [27] can be used to generate random variables with discrete distribution, RWM is simpler and does not require complex set-up procedure. Indeed, RWM has been applied in [25, 26, 28]. Numerical results show the capability of this method [28]. The realization process is summarized as follows.

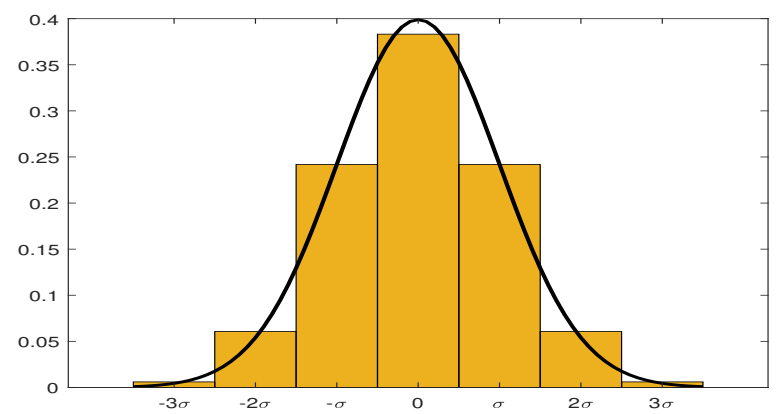

Figure 2: Discretization of forecast errors distribution

The Probability Distribution Function (PDF) is used to generate a set of possible options and corresponding probabilities based on forecast errors of the power generation and the different market prices, while for the FCR-N service activation states, the historical frequency is assumed as the probability for each possible state. As shown in Fig. 2, discretization and normalization are performed on the continuous probability distri- bution, generating 7 segments with an interval of standard deviation $(\sigma)$ [25]. The probability distribution of reserve service activation states is shown in Fig. 3. To be more specific, the prediction error of the wind power can be obtained from [29]. In our case, its $\sigma$ is taken as $5 \%$ for Denmark. From [30, 31], a $\sigma$ of $10 \%$ is a reasonable estimation of the prediction error for day-ahead market price. The prediction errors are also assumed as $10 \%$ for the FCR-N market and regulating market price.

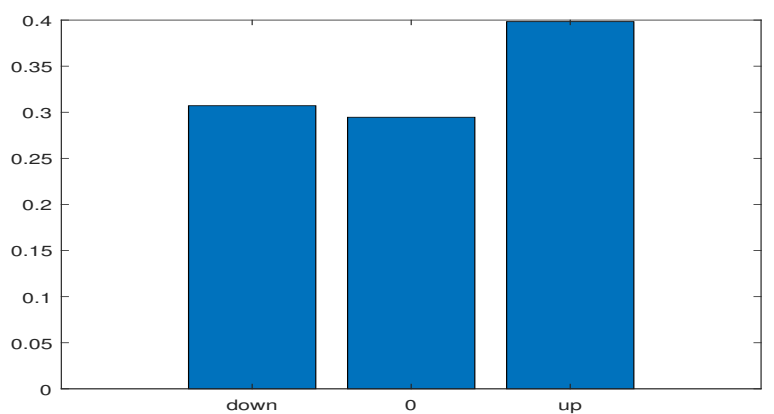

Figure 3: Reserve service activation state probability distribution

Afterwards, random numbers $\left(\epsilon_{t}^{w t}, \epsilon_{t}^{F C R-N}, \epsilon_{t}^{s p o t}, \epsilon_{t}^{u p}, \epsilon_{t}^{\text {down }}\right.$, $\epsilon_{t}^{R}$ ) ranging from [0,1] are generated for each hour. As in Fig. 4, the intervals where the random numbers fall in are taken as the corresponding options for each uncertain parameter. A scenario is therefore defined as a set of random numbers for each hour 


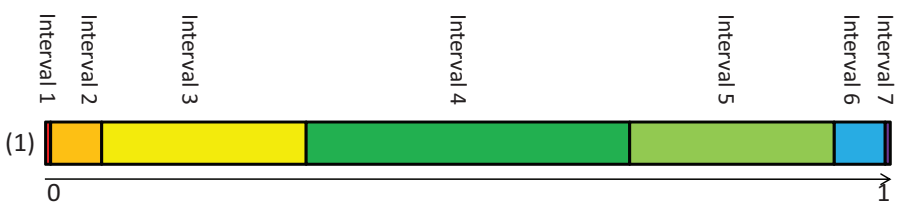

(2)

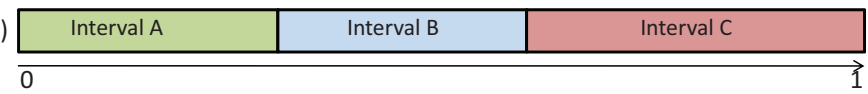

Figure 4: Accumulated probability distribution.(1):Power generation, FCR-N market prices, spot market prices and regulating market prices. (2): Reserve service activation states.

within a day:

$$
\begin{array}{r}
\omega=\left\{\epsilon_{1}^{w t}, \epsilon_{1}^{F C R-N}, \epsilon_{1}^{s p o t}, \epsilon_{1}^{u p}, \epsilon_{1}^{d o w n}, \epsilon_{1}^{R}, \epsilon_{2}^{w t}, \epsilon_{2}^{F C R-N}, \epsilon_{2}^{s p o t}, \epsilon_{2}^{u p},\right. \\
\left.\epsilon_{2}^{\text {down }}, \epsilon_{2}^{R}, \cdots, \epsilon_{T}^{w t}, \epsilon_{T}^{F C R-N}, \epsilon_{T}^{\text {spot }}, \epsilon_{T}^{u p}, \epsilon_{T}^{\text {down }}, \epsilon_{T}^{R}\right\}
\end{array}
$$

A typical scenario is shown in Fig. 5, where the uncertain parameters in a day are all determined with certain values. For example, in the first hour, the power is no more uncertain parameter, but fixed at just below $15 \mathrm{MWh}$. With all the scenarios, the stochastic programming problem is transformed into its deterministic equivalent. It can also be observed that the spot market prices intersect with the FCR-N market prices indicating profitability of biding in the FCR-N market.

In order to obtain the probability of each scenario, $Z_{\omega, t, i, j}$ is introduced to indicate the MCS results where $i$ is the uncertain parameter index and $\mathrm{j}$ is the interval index. The rule is that originally $Z_{\omega, t, i, j}$ are all set as 0 . When the corresponding interval is taken in the simulation, the related $Z_{\omega, t, i, j}$ is changed into 1. Suppose $\pi_{i, j}$ is the probability of the corresponding interval being taken, which is neither time nor scenario dependent, the normalized probability [25] of scenario $\omega$ is then:

$$
\pi_{\omega}=\frac{\prod_{t=1}^{T} \prod_{i=1}^{I} \sum_{j=1}^{J}\left(Z_{\omega, t, i, j} \pi_{i, j}\right)}{\sum_{\omega}^{\Omega} \prod_{t=1}^{T} \prod_{i=1}^{I} \sum_{j=1}^{J}\left(Z_{\omega, t, i, j} \pi_{i, j}\right)}
$$

\subsection{Scenario reduction}

Large number of scenarios usually indicate better approximation of the original problem, but also with longer computation time and larger complexity. In this research, the simultaneous backward method (SBM) which concurrently considers scenario distance and scenario probability is employed. $\mathrm{Nu}$ merical tests have shown that SBM provides accurate solutions to the optimal reduction problem [32] and is also used in researches such as [25]. The principle of scenario reduction is to reduce the scenario amount by deleting scenarios with lower probability and bundling similar scenarios, while keeping the characteristics as much as possible. The SBM is described as follows:

1. Consider $\Omega$ as the initial scenario set. The distance matrix $D T$ is defined where $\omega, \omega^{\prime} \in \Omega$ :

$$
D T_{\omega, \omega^{\prime}}= \begin{cases}\sqrt{\sum_{t=1, i=1, j=1}^{T, I J}\left(Z_{\omega, t, i, j}-Z_{\omega^{\prime}, t, i, j}\right)^{2}} & \omega \neq \omega^{\prime} \\ \operatorname{Inf} & \omega=\omega^{\prime}\end{cases}
$$

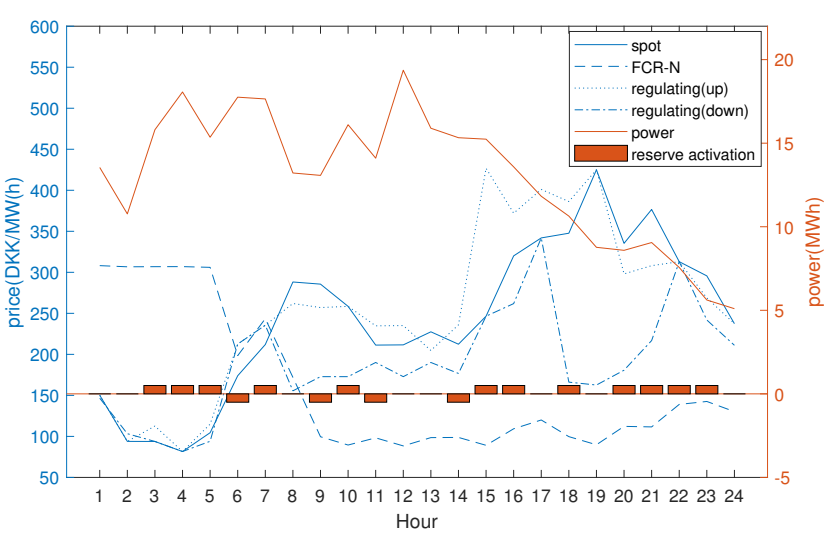

Figure 5: A typical scenario for 2nd November, 2017 with 1 indicating upward regulation, -1 being downward and 0 being reserve services not activated.

2. Define probability-distance matrix $P D$ as :

$$
P D_{\omega, \omega^{\prime}}=\pi_{\omega} D T_{\omega, \omega^{\prime}}
$$

3. Select $d, r$ where $P D_{d, r}$ is the smallest entry in the matrix $P D$. Delete scenario d in scenario set $\Omega, \pi_{r}=\pi_{r}+\pi_{d}$.

4. Delete the row $\mathrm{d}$ and column $\mathrm{d}$ in distance matrix DT.

5. Repeat the steps 2-4 until the required scenario amount is obtained.

\subsection{Mathematical model}

In order to verify the financial benefit of integrating the RESS and participating the FCR-N market, three cases are studied. In the base case, the wind farm without the storage system participates the spot market only and bids all the predicted power generation into the spot market, the revenue of which for a whole year is as Eq. (5). In case 1, the wind farm purchases RESS and participates the spot market, while bids are made in both the spot market and the FCR-N market in case 2.

$$
R^{\text {base }}=\sum_{d}^{D} \sum_{\omega=1}^{\Omega} \pi_{\omega, d} \sum_{t=1}^{T}\left\{E P_{t, \omega, d} P_{t, \omega, d}^{w t} 1\right\}
$$

\subsubsection{Case 1}

After the RESS is introduced into the system, the wind farm can perform arbitrage in the spot market. The yearly revenue is:

$$
R^{\text {case } 1}=\sum_{d}^{D} \sum_{\omega=1}^{\Omega} \pi_{\omega, d} \sum_{t=1}^{T}\left\{E P_{t, \omega, d} P_{t, \omega, d}^{s p o t} 1\right\}
$$

The benefit is considered as revenue difference before and after RESS introduction. The economic analysis is performed with 20 year's period since this is the wind turbine's lifetime. The net present value (NPV) of benefit is:

$$
\mathrm{NPV}^{1}{ }^{1}=\mathrm{NPV}-\mathrm{R}^{1}-\mathrm{NPV}-\mathrm{R}^{b}=\sum_{y=1}^{20} \frac{R^{\text {case } 1}-R^{\text {base }}}{\left(1+d_{r}\right)^{y-1}}
$$


where the superscript $b$ and 1, 2 (in following section) stand for the base case, case 1 and case 2 respectively.

The cost is considered as three parts: the initial investment of the RESS and the bi-directional inverter, the replacement cost (the cost of replacing the RESS and inverter with new one at the end of their lifetime), and the operation and maintenance cost (1\% of investment each year for both) [33]. In case 1 and 2 , two scenarios are considered concerning the price of retired battery, which is $15 \%$ of the brand new EV battery price in the optimistic scenario and $30 \%$ in the pessimistic scenario. The NPV of the cost is therefore:

$$
\begin{array}{r}
\text { NPV-C }=P^{i n v} \lambda^{i n v}\left[1+\frac{1}{\left(1+d_{r}\right)^{10}}+\sum_{y=1}^{20} \frac{r_{O \& M}}{\left(1+d_{r}\right)^{y-1}}\right] \\
+\alpha_{i} N E^{E V B} \lambda^{E V B}\left[1+\frac{1}{\left(1+d_{r}\right)^{7}}+\frac{1}{\left(1+d_{r}\right)^{14}}+\sum_{y=1}^{20} \frac{r_{O \& M}}{\left(1+d_{r}\right)^{y-1}}\right]
\end{array}
$$

where the inverter is assumed to be replaced after 10 year's operation, while the replacement for the RESS is done each 7 years, as specified in Table 1.

\section{Obj.}

$$
\text { Max. NPV-P }=\text { NPV-B }{ }^{1}-\mathrm{NPV}-\mathrm{C}
$$

S.t.

$$
\begin{gathered}
P^{i n v} \geq 0 \\
E^{c a p}=N E^{E V B} \mathrm{SoH}, N \geq 0 \\
P_{t, \omega, d}^{s p o t}=P_{t, \omega, d}^{s p o t, w t}+P_{t, \omega, d}^{d i s}, \forall t, \forall \omega, \forall d \\
P_{t, \omega, d}^{c h, w t}+P_{t, \omega, d}^{s p o t, w t}=P_{t, \omega, d}^{w t}, \forall t, \forall \omega, \forall d \\
P_{t, \omega, d}^{c h}=P_{t, \omega, d}^{c h, w t}, \forall t, \forall \omega, \forall d \\
E_{t+1, \omega, d}^{c h a r g e}=E_{t, \omega, d}^{c h a r g e}+\left(\eta^{c h} \eta^{\text {inv }} P_{t, \omega, d}^{c h}-\frac{P_{t, \omega, d}^{d i s}}{\eta^{d i s} \eta^{i n v}}\right) 1, \forall t, \forall \omega, \forall d \\
S o C_{m i n} E^{c a p} \leq E_{t, \omega, d}^{c h a r g e} \leq S o C_{m a x} E^{c a p}, \forall t, \forall \omega, \forall d \\
E_{1, \omega, d}^{c h a r g e}=E_{T+1, \omega, d}^{c h a r g e}=E_{\text {initial }}^{\text {charge }}, \forall \omega, \forall d \\
0 \leq P_{t, \omega, d}^{s p o t, w t} \leq P_{t, \omega, d}^{w t}, \forall t, \forall \omega, \forall d \\
0 \leq P_{t, \omega, d}^{c h, w t} \leq P_{t, \omega, d}^{w t}, \forall t, \forall \omega, \forall d \\
0 \leq P_{t, \omega, d}^{c h} \leq P^{i n v}, \forall t, \forall \omega, \forall d \\
0 \leq P_{t, \omega, d}^{\text {dis }} \leq P^{i n v}, \forall t, \forall \omega, \forall d \\
P_{t, \omega, d}^{c h} P_{t, \omega, d}^{d i s}=0, \forall t, \forall \omega, \forall d
\end{gathered}
$$

The objective function is the minus NPV of profit of the wind farm owner. In (10) and (11), the capacity of inverter and RESS are constrained as continuous and discrete variables respectively. (12) states the bidden electricity in the spot market while (13) shows the electricity balance of the wind farm. (14) indicates that wind power is the only charging source. The SoC balance, and upper/lower limits of SoC are shown in (15) (16). To guarantee the energy will be used out at the end of each day, (17) is applied as boundary conditions. (18) and (19) ensures the energy that flows into the spot market or the RESS is less than the generated energy. In (20) and (21), the constraints from inverter size are applied. By nature, the RESS cannot be charged and discharged simultaneously, which is stated in (22) as a combinational constraint.

Binary pair of variables, $\delta_{t, \omega, d}^{c h} / \delta_{t, \omega, d}^{d i s}$ are introduced to help linearize (22), which represent the charging/discharging state of the RESS. The big M method is implemented in this work to linearize the bi-linear term, where $M_{1}$ and $M_{2}$ in later paragragh are arbitrarily big number, which substitutes (22) with:

$$
\begin{aligned}
\delta_{t, \omega, d}^{c h}, \delta_{t, \omega, d}^{d i s} & \in\{0,1\}, \delta_{t, \omega, d}^{c h}+\delta_{t, \omega, d}^{d i s} \leq 1, \forall t, \forall \omega, \forall d \\
0 & \leq P_{t, \omega, d}^{c h} \leq M_{1} \delta_{t, \omega, d}^{c h}, \forall t, \forall \omega, \forall d \\
0 & \leq P_{t, \omega, d}^{d i s} \leq M_{1} \delta_{t, \omega, d}^{d i s}, \forall t, \forall \omega, \forall d
\end{aligned}
$$

\subsubsection{Case 2}

In case 2 , the yearly revenue for the wind farm owner comprises the revenue from the day-ahead electricity market, from the bidden capacity in the FCR-N market and from the FCR$\mathrm{N}$ service activation energy which is settled per MWh with the regulating power prices (RPP) [34]. For the FCR-N market, the Danish TSO Energinet requires simultaneous and symmetrical upward and downward regulation reserve bid [34]. Therefore, the upward bids and downwards bids can be described with one term $R_{t, \omega, d}$.

$$
\begin{array}{r}
R^{\text {case } 2}=\sum_{d}^{D} \sum_{\omega=1}^{\Omega} \pi_{\omega, d} \sum_{t=1}^{T}\left\{E P_{t, \omega, d} P_{t, \omega, d}^{s p o t} 1+R_{t, \omega, d} F C R N_{t, \omega, d}\right. \\
\left.+P_{t, \omega, d}^{a c t i, u p} R P P_{t, \omega, d}^{u p} 1-P_{t, \omega, d}^{\text {ch,down }} R P P_{t, \omega, d}^{\text {down }} 1\right\}
\end{array}
$$

Obj.

$$
\text { Max. NPV-P }=\text { NPV-B }{ }^{2}-\mathrm{NPV}-\mathrm{C}
$$

S.t.

$$
\begin{gathered}
(10)-(12) \\
P_{t, \omega, d}^{c h, w t}+P_{t, \omega, d}^{s p o t, w t}=P_{t, \omega, d}^{w t}-R_{t, \omega, d}, \forall t, \forall \omega, \forall d \\
P_{t, \omega, d}^{c h}=P_{t, \omega, d}^{c h, w t}+P_{t, \omega, d}^{c h, u p}+P_{t, \omega, d}^{c h, d o w n}, \forall t, \forall \omega, \forall d \\
(15)-(17) \\
P_{t, \omega, d}^{a c t i, u p}=\eta^{u p} \delta_{t, \omega, d}^{u p} R_{t, \omega, d}, \forall t, \forall \omega, \forall d \\
0 \leq P_{t, \omega, d}^{c h, u p} \leq\left(1-\eta^{u p}\right) \delta_{t, \omega, d}^{u p} R_{t, \omega, d}, \forall t, \forall \omega, \forall d \\
P_{t, \omega, d}^{c h, d o w n}=\eta^{d o w n} \delta_{t, \omega, d}^{d o w n} R_{t, \omega, d}, \forall t, \forall \omega, \forall d \\
R_{t, \omega, d} \geq 0.3 \vee R_{t, \omega, d}=0, \forall t, \forall \omega, \forall d \\
R_{t, \omega, d} \leq P_{t, \omega, d}^{w t}, \forall t, \forall \omega, \forall d \\
\left.R_{t, \omega, d} 1 \leq \min _{S o} C_{\text {max }} E^{c a p}-E_{t, \omega, d}^{c h a r g e}, P^{i n v} 1\right\}, \forall t, \forall \omega, \forall d \\
(18)-(21),(23)-(25)
\end{gathered}
$$

The objective function is the net present value of profit, where the NPV-C can be calculated as (8), and $R_{\text {case } 1}$ has to 
be replaced as $R_{\text {case } 2}$ for the NPV-B in Eq. (7). (28) sets the new electricity balance of the wind farm considering the reserved capacity for upward regulation. The charging power is stated as (29) where $P_{t, \omega, d}^{c h, u p}$ and $P_{t, \omega, d}^{c h, d o w n}$ denoting the potential inflow of electricity from the activated wind turbines if upward regulation is needed and from activated RESS if downward regulation is needed, respectively. (30) - (32) defines aforementioned $P_{t, \omega, d}^{a c t i, u p}, P_{t, \omega, d}^{c h, u p}$ and $P_{t, \omega, d}^{c h, d o w n}$, where, $\delta_{t, \omega, d}^{u p}$ and $\delta_{t, \omega, d}^{\text {down }}$ are a set of known binary numbers indicating if the TSO requires upward/downward regulations, and $\eta^{u p}$ and $\eta^{\text {down }}$, both assumed to be $10 \%$, are the percentages of electricity flowing into or receiving from the FCR-N market since the capacity is what the FCR-N market really needs to maintain the frequency stability. When secondary frequency reserves (aFRR) are activated, the TSO releases the FCR-N reserve services, which happens 150 seconds [34] after the frequency deviation, and the wind farm owner can collect the rest electricity generated from the wind turbines with the RESS. The minimum bidden FCR-N capacity is $0.3 \mathrm{MW}$ [34], which is constrained as (33). Hourly bidden upward and downward regulation capacities are constrained as (34) and (35) respectively. The constraints (10) - (12), (15) (17), (18) - (21) and (23) - (25) still apply to case 2.

Likewise, the big M method with binary variables $\delta_{t, \omega, d}^{1} /$ $\delta_{t, \omega, d}^{2}$ indicating whether is forwarded to the FCR-N market is performed on constraint (33). Then, it can be rewritten as:

$$
\begin{gathered}
\delta_{t, \omega, d}^{1}, \delta_{t, \omega, d}^{2} \in\{0,1\}, \delta_{t, \omega, d}^{1}+\delta_{t, \omega, d}^{2}=1, \forall t, \forall \omega, \forall d \\
-M_{2}\left(1-\delta_{t, \omega, d}^{1}\right) \leq R_{t, \omega, d} \leq M_{2}\left(1-\delta_{t, \omega, d}^{1}\right), \forall t, \forall \omega, \forall d \\
-M_{2}\left(1-\delta_{t, \omega, d}^{2}\right)+0.3 \leq R_{t, \omega, d}, \forall t, \forall \omega, \forall d
\end{gathered}
$$

The aforementioned model can be implemented by the wind farm owner for daily operations with a much shorter optimization span. However, for the strategy maker who needs to include the equipment sizes as the optimization variables and usually performs the optimization with a year's span (with constraint (17) as daily boundary conditions), such binary variables with high dimensionality in the model will severely undermine the computation efficiency and can even cause the model untractable with existing commercial solvers. In order to enhance the implementation performance of the large-scale MILP problem, following assumptions concerning the wind farm owner's behaviours are made to avoid the binary variables in the model: a) Always and only forward bids in the FCR-N market when power generation is over $0.3 \mathrm{MW}$ and the predicted FCR-N market price is higher than $80 \%$ of spot market price and b) Never bids RESS-stored electricity in the spot market if predicted price is non-positive.

The first assumption is made with respect to the minimum bids requirement in the FCR-N market and taking into account the potential electricity inflow and revenue from the reserve service activation. Afterwards, constraint (33) can be transformed as:

$$
\left\{\begin{array}{ll}
R_{t, \omega, d} \geq 0.3 & \delta_{t, \omega, d}^{3} \delta_{t, \omega, d}^{4}=1 \\
R_{t, \omega, d}=0 & \delta_{t, \omega, d}^{3} \delta_{t, \omega, d}^{4}=0
\end{array}, \forall t, \forall \omega, \forall d\right.
$$

with $\delta_{t, \omega, d}^{3}$ indicating if the power generation is over $0.3 \mathrm{MW}$, $\delta_{t, \omega, d}^{4}$ indicating if the FCR-N market price is over $80 \%$ of the spot market price.

Simultaneous charging and discharging will incur electricity waste due to inefficiency, which definitely results in revenue loss when the spot market price is positive [21]. Therefore, the constraint (22) can be decoupled naturally with the above assumptions. As a result, the constraints (23) - (25) can be replaced with:

$$
P_{t, \omega, d}^{d i s} \leq M_{3}\left\{\left[1-\delta_{t, \omega, d}^{3} \delta_{t, \omega, d}^{4}\left(\delta_{t, \omega, d}^{u p}+\delta_{t, \omega, d}^{d o w n}\right)\right] \vee\left(1-\delta_{t, d}^{5}\right)\right\}, \forall t, \forall \omega, \forall d
$$

where $\delta_{t, \omega, d}^{5}$ will be zero if the spot market price is non-positive. In essence, the constraint (40) limits that the RESS cannot discharge if the spot market price is non-positive or if the reserve services are activated.

\subsection{Assumptions}

Apart form the assumptions made above, some other assumptions are made in the follows.

a) The predicted values for the power generation, the spot market prices, the FCR-N market prices, the regulating market prices, and the reserve activation states are assumed to be based on historical data for scenario generation.

b) The wind farm is assumed to be able to make predictions before the market closure, which is usually a day before realtime transaction.

c) The bids in the spot market and the FCR-N market are both assumed to be fully accepted.

d) To account for the impacts on performance of retired EV battery, the capacity, and the maximum and minimum charging/discharging is limited to short range in this work. The retired batteries are not designed to perform market arbitrage either, which means electricity from the day-ahead market is not used to charge the RESS.

\section{Case Study}

In this part, several cases are studied to demonstrate the proposed method. The FCR-N market prices are from Energinet [35] while the spot market and regulating market prices are from Nordpool [36]. The mathematical model is solved with CPLEX [37] based on YALMIP [38] toolbox on MATLAB.

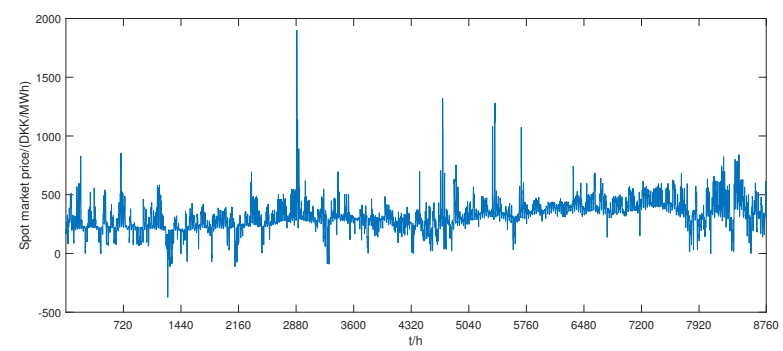

Figure 6: The spot market prices for a year 
Table 1: Economical analysis parameters

\begin{tabular}{lcc}
\hline Parameter & Values & References \\
\hline Wind turbine lifetime & 20 years & \\
Bi-directional inverter lifetime & 10 years & {$[39]$} \\
RESS secondary service lifetime & 7 years & {$[40,41]$} \\
Discount rate $d_{r}$ & $5 \%$ & \\
O\&M ratio $r_{O \& M}$ for RESS and inverter & $1 \% /$ year & {$[33]$} \\
Bi-directional inverter price/kWh & $1000 \mathrm{DKK}$ & \\
Brand new EV battery price/kWh & $1787 \mathrm{DKK}$ & {$[42]$} \\
Brand new EV battery stack capacity & $24 \mathrm{kWh}$ & \\
SoH'of retired EV batteries & $80 \%$ & {$[43-45]$} \\
Maximum charging/discharging rate & By inverter & \\
Charging/discharging efficiency & $95 \%$ & {$[43]$} \\
Inverter efficiency & $98 \%$ & {$[46]$} \\
Maximum SoC & $80 \%$ & \\
Minimum SoC & $20 \%$ & \\
Initial(End-of-day) SoC(case 1) & $20 \%$ & \\
Initial(End-of-day) SoC(case 2) & $35 \%$ & \\
\hline
\end{tabular}

* State of health, the ratio between usable capacity and nominal capacity.
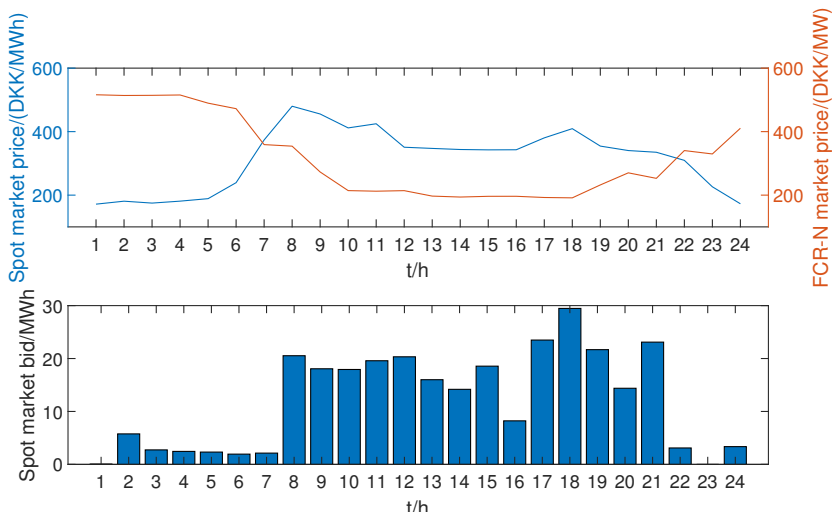

$\mathrm{t} / \mathrm{h}$

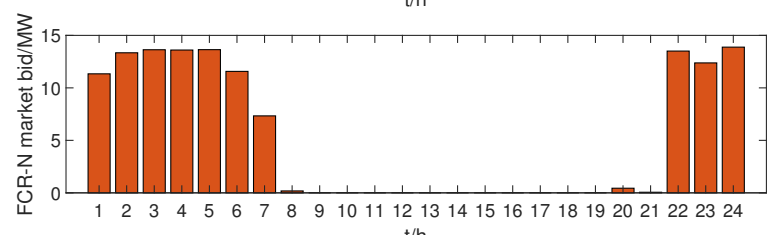

$\mathrm{t} / \mathrm{h}$

\subsection{Reference wind farm}

The wind farm near the Danish island Sprogoe consist of seven Vestas V90-3 MW wind turbines. Using WindPro and the mesoscale wind data from ERA5, the hourly electricity production from each of the wind farm has been calculated between November 1, 2017 and October 31, 2018. The expected lifetime of an offshore wind farm is 20-25 years [47]. The location of Sprogoe is in the middle of the Great Belt of Denmark, which had 11,357,037 personal vehicles passing by in 2018 [48], making it an ideal position for a nearby EV charging station.

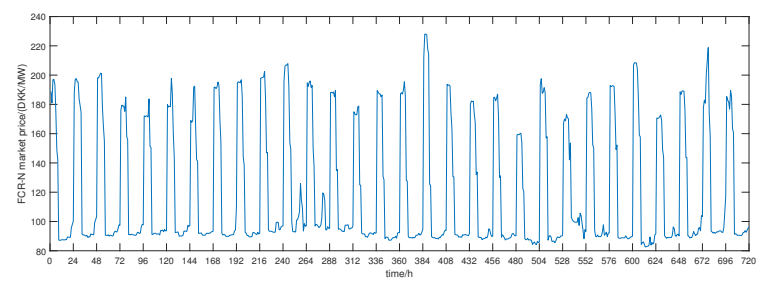

Figure 7: The FCR-N market prices from 31/12/2017 to 28/1/2018

\subsection{Retired EV battery}

Nissan Leaf is the bestselling EV model in Norway (over 50,000 in total) [49], and had a market share of $50 \%$ of the Danish EV market in 2018 [50]. The first 24kWh Leaf model entered the Danish market around 2011 and was warrantied for 8 years life span or 100,000 mileage [51], which makes today around the peak of retirement for this model. The retired EV batteries are connected in stack to work as a RESS for the hybrid system, the capacity of which (i.e. number of connected batteries) and the installed inverter capacity are optimized to achieve maximum profit. The specification of the RESS and inverter can be found in Table 1. Two scenarios concerning the price of retired EV battery are considered. In the optimistic scenario, the price is $15 \%$ of its brand new model price. While in the pessimistic scenario, the price is considered as $30 \%$ of that.

Figure 8: Bids in the spot market and the reserve market in the optimistic scenario

\subsection{Optimization results}

In the implementation of the stochastic programming framework, to account the uncertainties in the model, a large number of scenarios (1000 in this case) have been generated with MCS and RWM. A SBM is afterwards applied to reduce the generated scenarios to 20 remained, in line with [28]. A sensitivity analysis is provided in section 3.4 to investigate the influence of the amount of the remained scenarios on the final results.

In this study, two cases with both the optimistic and pessimistic scenarios are examined. As in Table 2, the wind farm cannot recover its investment introducing a RESS and an inverter even in the optimistic scenario in case 1, where the wind farm only forwards bids in the spot market, which is primarily due to the high inverter and battery prices considering the spot market prices are highly variable as in Fig. 6, with a daily average standard deviation of $66.8 \mathrm{DKK} / \mathrm{MWh}$.

While in case 2 under the optimistic scenario, the wind farm would like to install 1615 single retired batteries to form a RESS with a disposable capacity of $30.0 \mathrm{MWh}$ due to battery degradation and an inverter of 13.9 MW, which would lead to an annual revenue increase of $6.4 \mathrm{MDKK}$. As the result indicates, the wind farm will recover its initial investment after 4.3 years, with a overall return on investment (RoI) of $72.1 \%$ over 20 years. In the pessimistic scenario, the wind farm would purchase a much smaller system with 895 single retired batteries and a 9.4 MW inverter. Even though with the yearly revenue dropping down by $1.8 \mathrm{MDKK}$, payback year increasing by 1.1 year, and almost halved RoI, the hybrid system is still on a financially competitive level.

The bids forwarded in both the spot market and the FCR-N market are taken as scenario-weighted mean values. In a typical day the spot market prices cross the FCR-N market prices, which is usually the case as shown in Fig. 7 where the FCR-N 
Table 2: Optimization results

\begin{tabular}{lccccccc}
\hline Scenario & Battery Number & Inverter Size & Yearly Revenue & NPV-C & NPV-P & RoI $^{2}$ & PBY $^{3}$ \\
\hline Base case & \multicolumn{7}{c}{$18.20 \mathrm{M}^{4}$} \\
Case 1(optimistic) & 0 & 0 & $18.20 \mathrm{M}$ & 0 & 0 & & \\
Case 1(pessimistic) & 0 & 0 & $18.20 \mathrm{M}$ & 0 & 0 & & \\
\hline Case 2(optimistic) & 1615 & $13.88 \mathrm{MW}$ & $24.59 \mathrm{M}$ & $48.60 \mathrm{M}$ & $35.04 \mathrm{M}$ & $72.10 \%$ & 4.27 \\
Case 2(pessimistic) & 895 & $9.41 \mathrm{MW}$ & $22.75 \mathrm{M}$ & $43.44 \mathrm{M}$ & $16.10 \mathrm{M}$ & $37.07 \%$ & 5.34 \\
\hline
\end{tabular}

1 The optimization span is a year with the daily boundary conditions and a time resolution of an hour.

2 Return on Investment, $R o I=\frac{\text { NPV-B }}{\text { NPV-C }}$

3 Payback Year: time when the net present benefit equals investment.

4 Million DKK.

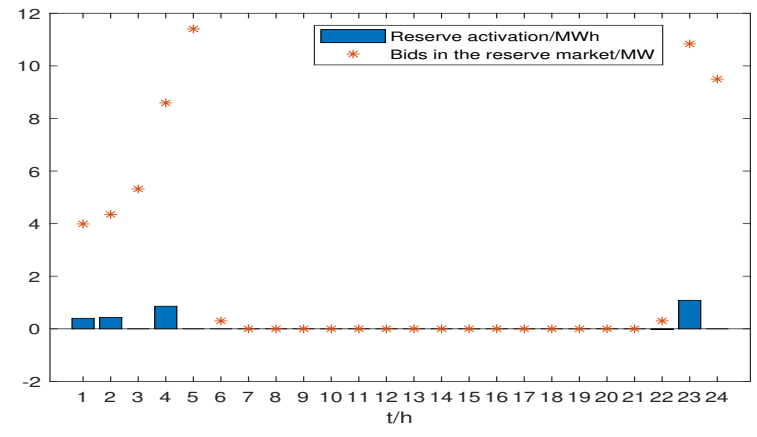

Figure 9: Bids in the FCR-N market and reserve service activation in the optimistic scenario

market prices show a strong regularity of starting at a high level, dropping down drastically and bouncing back a little within a day. As a result, the bids made in the FCR-N market shows a similar pattern as in Fig. 8, being on a high level during the start as well as end of the day and around 0 in the middle of the day, when most of the wind power is transmitted to the spot market. Despite of this, the wind farm still receives a NPV of profit increase of 35.0 MDKK over 20 years in the optimistic scenario, verifying the high profitablity of participating the FCR-N market.

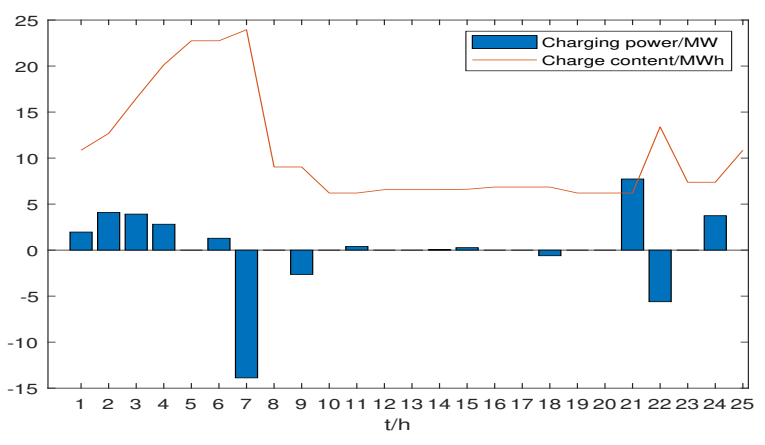

Figure 10: Energy content and charge/discharge in the optimistic scenario

In Fig. 9, the reserve service activation is depicted in two different directions, indicating upward regulation and downward regulation for a certain scenario respectively. In the hours (3rd, 5th 6 th, 22nd and 24th), the reserve services are not activated,

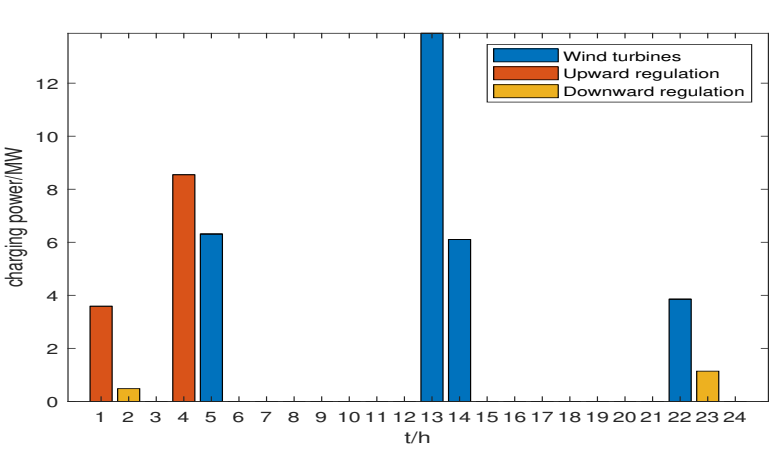

Figure 11: Charging power source in the optimistic scenario

though bids are forwarded to the market, which incurs loss in the revenue since the FCR-N market prices in the 22nd hour (334 DKK/MW) are lower than that of the spot market (344 $\mathrm{DKK} / \mathrm{MWh}$ ). However, this does not indicate the model is defected, since assuming the wind farm can precisely predict the frequency regulation directions a day before to make decisions as dictated in the model with binary variables is far too idealistic. The assumption that the wind farm always bids in the FCR-N market as long as the price is over $80 \%$ of the spot market price is a compromise between situations when service is upwards activated so extra electricity can be reserved thus with extra revenues and cases when there is no activation so with economic losses, which makes the model more down to earth and the profit result more reliable.

In a typical scenario, the electricity flow profile of the RESS is as Fig. 10, where the RESS discharges with a high rate at some moment in order to level off the charged energy within a day to satisfy the boundary conditions, which results in a highcapacity inverter. The charging profile is further divided in Fig. 11 indicating that the wind power and the reserve service activation by upward regulations are the major sources of battery charging power.

\subsection{Sensitivity analysis}

In this section, a sensitivity analysis is employed to investigate the influence on the planning and financial results of the remained scenarios number after applying the SBM. We specifically focus on case 2 for the optimistic scenario. The case when the stochastic framework is not applied is also included, 
Table 3: Sensitivity analysis results

\begin{tabular}{ccccc}
\hline Remained scenarios & Battery Number & Inverter size & NPV-P & Normalized computation time \\
\hline Non-stochastic & 1622 & $12.99 \mathrm{MW}$ & $30.96 \mathrm{MDKK}$ & 0.015 \\
5 & 1640 & $13.83 \mathrm{MW}$ & $34.98 \mathrm{MDKK}$ & 0.09 \\
10 & 1615 & $13.89 \mathrm{MW}$ & $35.08 \mathrm{MDKK}$ & 0.25 \\
20 & 1615 & $13.88 \mathrm{MW}$ & $35.04 \mathrm{MDKK}$ & 1 \\
\hline
\end{tabular}

in which the markets prices, wind power and regulating statuses are all historic data. The solving time is normalized based on the case where 20 scenarios remain after the scenario reduction technique. The equipment sizes and the normalized solving times are shown in Table 3.

From the sensitivity analysis results, following conclusions can be obtained: 1) The computation time is highly influenced by the number of remained scenarios. When the scenario number doubles, the solving process takes 3-4 times longer. 2) The planning results stabilise at larger number of scenarios. In this case, 10 remained scenarios give almost the same results as 20 scenarios. 3) In this case, 10 remained scenarios gives the best performance in terms of optimization accuracy and computation time.

\section{Conclusion}

In this study, a hybrid wind turbine-retired battery storage system is proposed to participate both the spot market and the FCR-N market to increase the wind farm owner's profit. The uncertainties are modelled with a scenario-based stochastic programming method. The scenarios are generated with MCS and RWM. Afterwards, they are applied to SBM to be reduced to enhance the computational efficiency. The hybrid system are investigated in two cases. In the first case, the wind farm participate in the spot market only. While in the second case, the wind farm also forwards bids in the FCR-N market. Two scenarios (optimistic/pessimistic) are raised in terms of the price of retired $\mathrm{EV}$ batteries to examine its influence on the planning. A sensitivity analysis is performed at last to provide insights regarding the influence of remained number of scenarios on the optimization results.

The optimization results show that by integrating the retired EV batteries and forwarding bids in the FCR-N market, the system can increase the net present value of profit by 35.0 MDKK in the optimistic scenario and 16.1 MDKK in the pessimistic scenario. Compare case 1 with case 2, participating FCR-N market is the major reason of the increased profit when the winf farm integrates retired EV batteries. The sensitivity analysis concludes that 10 remained scenarios would have the best performance regarding optimziation accuracy and computation efficiency. Considering the fact that brand new EV battery price was dropping dramatically over the years $(73 \%$ drop from 2010 - 2016) [42] and is expected to be further decreased down to 109 $\$ / \mathrm{kWh}$ in 2025 and $73 \$ / \mathrm{kWh}$ in 2030 [42], the proposed system is highly financially favourable and provides an alternative to repurpose the retired EV batteries.

\section{References}

[1] J. Kester, L. Noel, G. Zarazua de Rubens, B. K. Sovacool, Promoting Vehicle to Grid (V2G) in the Nordic region: Expert advice on policy mechanisms for accelerated diffusion, Energy Policy 116 (February) (2018) 422-432 (2018). doi:10.1016/j.enpol.2018.02.024.

URL https://doi.org/10.1016/j.enpol.2018.02.024

[2] A. Ajanovic, R. Haas, Electric vehicles: solution or new problem?, Environment, Development and Sustainability 20 (s1) (2018) 7-22 (2018). doi:10.1007/s10668-018-0190-3.

URL https://doi.org/10.1007/s10668-018-0190-3

[3] International Energy Agency (IEA), Global EV Outlook 2017: Two million and counting, IEA Publications (2017) 1-71 (2017). doi:10.1787/9789264278882-en.

[4] B. K. Sovacool, J. Axsen, W. Kempton, The Future Promise of Vehicleto-Grid (V2G) Integration: A Sociotechnical Review and Research Agenda, Annual Review of Environment and Resources 42 (1) (2017) 377-406 (2017). doi:10.1146/annurev-environ-030117-020220.

URL http://www.annualreviews.org/doi/10.1146/annure v-environ-030117-020220

[5] L. Noel, G. Zarazua de Rubens, B. K. Sovacool, J. Kester, Fear and loathing of electric vehicles: The reactionary rhetoric of range anxiety, Energy Research and Social Science 48 (April 2018) (2019) 96-107 (2019). doi:10.1016/j.erss.2018.10.001.

URL https://doi.org/10.1016/j.erss.2018.10.001

[6] B. K. Sovacool, R. F. Hirsh, Beyond batteries: An examination of the benefits and barriers to plug-in hybrid electric vehicles (PHEVs) and a vehicle-to-grid (V2G) transition, Energy Policy 37 (3) (2009) 1095-1103 (2009). arXiv:0109122v5, doi:10.1016/j.enpol.2008.10.005.

[7] Z. Huang, Z. Xie, C. Zhang, S. H. Chan, J. Milewski, Y. Xie, Y. Yang, X. Hu, Modeling and multi-objective optimization of a stand-alone pv-hydrogen-retired ev battery hybrid energy system, Energy Conversion and Management 181 (2019) 80 - 92 (2019). doi:https://doi.org/10.1016/j.enconman.2018.11.079.

URL http://www.sciencedirect.com/science/article/pii/ S0196890418313414

[8] E. Martinez-Laserna, E. Sarasketa-Zabala, I. Villarreal Sarria, D. Stroe, M. Swierczynski, A. Warnecke, J. Timmermans, S. Goutam, N. Omar, P. Rodriguez, Technical viability of battery second life: A study from the ageing perspective, IEEE Transactions on Industry Applications 54 (3) (2018) 2703-2713 (May 2018). doi:10.1109/TIA.2018.2801262.

[9] Y. Tang, Q. Zhang, H. Li, Y. Li, B. Liu, Economic analysis on repurposed ev batteries in a distributed pv system under sharing business models, Energy Procedia 158 (2019) 4304 - 4310, innovative Solutions for Energy Transitions (2019). doi:https://doi.org/10.1016/j.egypro.2019.01.793. URL http://www.sciencedirect.com/science/article/pii/ S1876610219308318

[10] Bilimp, https://www.bilimp.dk/Nyhed?id=5855, [Online], accessed 29 January 2019 (2018).

[11] Elbil, https://elbil.no/english/norwegian-ev-market/, [Online], accessed 29 January 2019 (2018).

[12] B. Sweden, http://www.bilsweden.se/statistik/nyregistr eringar_per_manad_1/nyregistreringar-2017/definitiva-n yregistreringar-under-2017, [Online], accessed 29 January 2019 (2018).

[13] P. Enevoldsen, Onshore wind energy in Northern European forests: Reviewing the risks, Renewable and Sustainable Energy Reviews 60 (2016) 1251-1262 (2016). doi:10.1016/j.rser.2016.02.027.

URL http://dx.doi.org/10.1016/j.rser.2016.02.027

[14] I. Pineda, W. Pierre Tardieu, Annual combined onshore and offshore wind energy statistics (2018). doi:10.1016/j.preghy.2016.08.046. 
URL https://windeurope.org/wp-content/uploads/fil es/about-wind/statistics/WindEurope-Annual-Statistic s-2017.pdf

[15] P. Hou, P. Enevoldsen, J. Eichman, W. Hu, M. Z. Jacobson, Z. Chen, Optimizing investments in coupled offshore wind -electrolytic hydrogen storage systems in Denmark, Journal of Power Sources 359 (2017) 186197 (2017). doi:10.1016/j.jpowsour.2017.05.048.

URL http://dx.doi.org/10.1016/j.jpowsour.2017.05.048

[16] X. Luo, J. Wang, M. Dooner, J. Clarke, Overview of current development in electrical energy storage technologies and the application potential in power system operation, Applied Energy 137 (2015) 511-536 (2015). doi:10.1016/j.apenergy.2014.09.081.

URL http://dx.doi.org/10.1016/j.apenergy.2014.09.081

[17] B. Zakeri, S. Syri, Corrigendum to Electrical energy storage systems A comparative life cycle cost analysis [Renew. Sustain. Energy Rev. 42 (2015) 569596], Renewable and Sustainable Energy Reviews 53 (2015) 1634-1635 (2015). doi:10.1016/j.rser.2015.09.095.

URL http://dx.doi.org/10.1016/j.rser.2015.09.095

[18] J. Wen, W. Yao, R. Cai, J. Fang, X. Ai, J. Li, H. Xie, Multi-time-scale coordinated ramp-rate control for photovoltaic plants and battery energy storage, IET Renewable Power Generation 12 (12) (2018) 1390-1397 (2018). doi:10.1049/iet-rpg.2018.5190.

[19] J. Fang, Q. Zeng, X. Ai, Z. Chen, J. Wen, Dynamic optimal energy flow in the integrated natural gas and electrical power systems, IEEE Transactions on Sustainable Energy 9 (1) (2018) 188-198 (2018). doi:10.1109/TSTE.2017.2717600.

[20] H. Chen, T. N. Cong, W. Yang, C. Tan, Y. Li, Y. Ding, Progress in electrical energy storage system: A critical review, Progress in Natural Science 19 (3) (2009) 291-312 (2009). doi:10.1016/j.pnsc.2008.07.014. URL http://dx.doi.org/10.1016/j.pnsc.2008.07.014

[21] P. Hou, G. Yang, P. Enevoldsen, A. H. Nielsen, Cooperation of Offshore Wind Farm with Battery Storage in Multiple Electricity Markets, 2018 53rd International Universities Power Engineering Conference (UPEC) (2018) 1-6 (2018). doi:10.1109/UPEC.2018.8541864.

URL https://ieeexplore.ieee.org/document/8541864/

[22] L. Baringo, A. J. Conejo, Offering Strategy of Wind-Power Producer: A Multi-Stage Risk-Constrained Approach, IEEE Transactions on Power Systems 31 (2) (2016) 1420-1429 (2016). doi:10.1109/TPWRS.2015.2411332

[23] T. Dai, W. Qiao, Optimal bidding strategy of a strategic wind power producer in the short-term market, IEEE Transactions on Sustainable Energy 6 (3) (2015) 707-719 (2015). doi:10.1109/TSTE.2015.2406322.

[24] M. Jozef, P. Braun, M. Swierczynski, R. Diosi, D. Stroe, R. Teodorescu, Aalborg Universitet Optimizing a Hybrid Energy Storage System for a Virtual Power Plant for Improved Wind Power Generation: A Case Study for Denmark Optimizing a Hybrid Energy Storage System for a Virtual Power Plant for Improved Wind Power Generation: A (2011).

[25] T. Niknam, R. Azizipanah-Abarghooee, M. R. Narimani, An efficient scenario-based stochastic programming framework for multi-objective optimal micro-grid operation, Applied Energy 99 (2012) 455-470 (2012). doi:10.1016/j.apenergy.2012.04.017.

URL http://dx.doi.org/10.1016/j.apenergy.2012.04.017

[26] M. Bornapour, R. A. Hooshmand, M. Parastegari, An efficient scenario-based stochastic programming method for optimal scheduling of CHP-PEMFC, WT, PV and hydrogen storage units in micro grids, Renewable Energy 130 (2019) 1049-1066 (2019). doi:10.1016/j.renene.2018.06.113.

URL https://doi.org/10.1016/j.renene.2018.06.113

[27] B. F. Nielsen, Stochastic simulation generation of random variables discrete sample space, lecture note for 02443 Stochastic simulation (2019).

[28] A. Ahmadi, M. Charwand, P. Siano, A. E. Nezhad, D. Sarno, M. Gitizadeh, F. Raeisi, A novel two-stage stochastic programming model for uncertainty characterization in short-term optimal strategy for a distribution company, Energy 117 (2016) 1-9 (2016). doi:10.1016/j.energy.2016.10.067.

URL http://dx.doi.org/10.1016/j.energy.2016.10.067

[29] B.-m. Hodge, D. Lew, M. Milligan, E. Gómez-lázaro, D. Flynn, J. Dobschinski, Wind Power Forecasting Error Distributions, The 11th Annual International Workshop on Large-Scale Integration of Wind Power into Power Systems as well as on Transmission Networks for Offshore Wind Power Plants Conference (March) (2012) 1-8 (2012)
doi:10.1109/JLT.1986.1074720.

[30] O. A. Karabiber, G. Xydis, Electricity price forecasting in the Danish dayahead market using the TBATS, ANN and ARIMA methods, Energies 12 (5) (2019). doi:10.3390/en12050928.

[31] M. Cerjan, A. Petričić, M. Delimar, HIRA model for short-term electricity price forecasting, Energies 12 (3) (2019). doi:10.3390/en12030568.

[32] N. Growe-Kuska, H. Heitsch, W. Romisch, Scenario reduction and scenario tree construction for power management problems, in: 2003 IEEE Bologna Power Tech Conference Proceedings,, Vol. 3, 2003, pp. 7 pp. Vol.3- (June 2003). doi:10.1109/PTC.2003.1304379.

[33] Y. Zhang, P. E. Campana, A. Lundblad, J. Yan, Comparative study of hydrogen storage and battery storage in grid connected photovoltaic system: Storage sizing and rule-based operation, Applied Energy 201 (2017) 397411 (2017). doi:10.1016/j.apenergy.2017.03.123.

URL http://dx.doi.org/10.1016/j.apenergy.2017.03.123

[34] Energinet.dk, Ancillary services to be delivered in denmark - tender conditions (2017).

[35] Energinet.dk, https://www.energidataservice.dk/, [Online], accessed 23 December, 2018.

[36] Nordpool, https://www.nordpoolgroup.com/, [Online], accessed 23 December, 2018.

[37] IBM-CPLEX, https://www.ibm.com/dk-da/analytics/cple $\mathrm{x}$-optimizer.

[38] J. Löfberg, Yalmip : A toolbox for modeling and optimization in matlab, in: In Proceedings of the CACSD Conference, Taipei, Taiwan, 2004 (2004).

[39] C. Hinkle, A. Millner, W. Ross, Bi-directional power architectures for electric vehicles, 2011 8th International Conference and Expo on Emerging Technologies for a Smarter World, CEWIT 2011 (2011) 1-6 (2011). doi:10.1109/CEWIT.2011.6135867.

[40] N. Jiao, S. Evans, Business Models for Repurposing a Second-Life for Retired Electric Vehicle Batteries, Green Energy and Technology (9783319699493) (2018) 323-344 (2018). doi:10.1007/978-3-31969950-9_13.

[41] H. Ambrose, D. Gershenson, A. Gershenson, D. Kammen, Driving rural energy access: A second-life application for electric-vehicle batteries, Environmental Research Letters 9 (9) (2014). doi:10.1088/17489326/9/9/094004.

[42] BNEF, Bloomberg New Energy Finance Report, Bnef (April) (2017) 160 (2017). doi:10.1111/j.1468-2427.1992.tb00177.x.

[43] M. Abdel-monem, O. Hegazy, N. Omar, K. Trad, P. V. Den, J. V. Mierlo, Lithium-ion Batteries : Comprehensive Technical Analysis of SecondLife Batteries for Smart Grid Applications Vito , Unit of Energy Technology Acknowledgments Keywords 1-16.

[44] Q. Zhai, K. Meng, Z. Y. Dong, J. Ma, Modeling and Analysis of Lithium Battery Operations in Spot and Frequency Regulation Service Markets in Australia Electricity Market, IEEE Transactions on Industrial Informatics 13 (5) (2017) 2576-2586 (2017). doi:10.1109/TII.2017.2677969.

[45] S. Hu, H. Sun, F. Peng, W. Zhou, W. Cao, A. Su, X. Chen, M. Sun, Optimization strategy for economic power dispatch utilizing retired EV batteries as flexible loads, Energies 11 (7) (2018). doi:10.3390/en11071657.

[46] P. Wolfs, An economic assessment of second use lithium-ion batteries for grid support An Economic Assessment of Second Use Lithium- Ion Batteries for Grid Support (2015).

[47] P. Hou, P. Enevoldsen, W. Hu, C. Chen, Z. Chen, Offshore wind farm repowering optimization, Applied Energy 208 (September) (2017) 834844 (2017). doi:10.1016/j.apenergy.2017.09.064.

[48] Storebaelt, https://www.storebaelt.dk/omstorebaelt/trafi ktal, [Online], accessed 29 January 2019 (2018).

[49] Elbilstatistikk, http://elbilstatistikk.no/?sort=2, [Online], accessed 23 December 2018 (2018)

[50] Nissan, https://denmark.nissannews.com/da-DK/releases/, [Online], accessed 23 December 2018 (2018).

[51] Nissan, https://www.greencarcongress.com/2010/07/nissan -to-warranty-leaf-battery-for-8-years-100000-miles- . html\#more, [Online], accessed 24 March 2018 (2010). 